\title{
Alveolarna ehinokokoza - širenje invazije illi do sada nedijagnosticirana zoonoza?
}

\author{
L. Vukres-Jazić, M. Sindičić̌ ${ }^{*}$ M. Bujanić, F. Martinković, T. Gomerčić i \\ D. Konjević
}

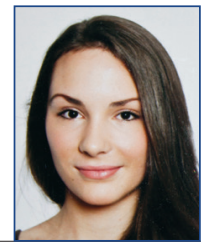

\section{Sažetak}

Alveolarna ehinokokoza opasna je parazitarna zoonoza prouzročena larvalnim stadijem trakavice Echinococcus multilocularis. Prenosi se tipično $u$ silvatičnom ciklusu, koji uključuje, prije svega, lisicu kao nositelja i kao posrednike različite vrste glodavaca. Ljudi kao posrednici u stvarnosti predstavljaju slijepu ulicu, no parazit u ljudi može prouzročiti tešku kliničku sliku. Do 1980. godine samo su četiri zemlje (Francuska, Njemačka, Švicarska i Austrija) bile prepoznate kao endemična područja za ovu bolest, a najnoviji podatci govore da je u međuvremenu prisutnost E. multilocularis zabilježena $\mathrm{u}$ lisica $\mathrm{u}$ barem 24 europske zemlje. Uzimajući u obzir da je alveolarna ehinokokoza, ukoliko se pravodobno

ne dijagnosticira i ne liječi, smrtonosna zoonoza, njezino širenje od velikog je javnozdravstvenog značenja. S ciljem održavanja ove bolesti pod kontrolom, potreban je stalni nadzor provođenjem epidemioloških istraživanja te praćenjem statusa populacije lisica kao životinja presudnih u održavanju životnog ciklusa ovoga parazita. Na temelju podataka prikupljenih iz brojnih istraživanja provedenih u posljednja dva desetljeća, u ovom preglednom članku stavljen je naglasak na opasnost koju alveolarna ehinokokoza predstavlja kao emergentna i re-emergentna bolest $\mathrm{u}$ sve većem broju europskih zemalja te ulogu divljih životinja u njezinu širenju.

Ključne riječi: Echinococcus multilocularis, alveolarna ehinokokoza, divlje životinje, zoonoza

\section{Uvod}

Alveolarna ehinokokoza je parazitarna zoonoza prouzročena larvalnim stadijem trakavice Echinococcus multilocularis. Široko je rasprostranjena po cijeloj sjevernoj hemisferi. Prenosi se ti-

pično u silvatičnom ciklusu koji uključuje lisicu ili drugog divljeg mesojeda kao nositelja i kao posrednike različite vrste glodavaca. Iako se radi o rjeđoj pojavi, javlja se i urbani ciklus, gdje su nositelji

Lana VUKRES - JAZIĆ, dr. med. vet., dr. sc. Magda SINDIČIĆ*, dr. med. vet., docentica, (dopisni autor, e-mail: magda.sindicic@vef.hr), dr. sc. Miljenko BUJANIĆ, dr. med. vet., dr. sc. Franjo MARTINKOVIĆ, dr. med. vet., docent, dr. sc. Tomislav GOMERČIĆ, dr. med. vet., izvanredni profesor, dr. sc. Dean KONJEVIĆ, dr. med. vet., izvanredni profesor, Veterinarski fakultet Sveučilišta u Zagrebu 
psi ili mačke. Posrednici, glodavci i ljudi kao slučajni nositelji larvalnog oblika, najčešće se invadiraju hranom i vodom zagađenom izmetom invadirane lisice $u$ kojem se nalaze jajašca trakavice (Torgerson i sur., 2010.).

Trendovi pokazuju kako rasprostranjenost E. multilocularis $\mathrm{u}$ Europi raste. Do 1980. godine samo su četiri zemlje (Francuska, Njemačka, Švicarska i Austrija) bile prepoznate kao endemična područja za ovu bolest (Eckert i Deplazes, 1999.). Od tada je ona sve češće prijavljivana u zemljama za koje se prije mislilo da su od nje slobodne (Davidson i sur., 2012.). Najnovije dostupne informacije govore da je trakavica $E$. multilocularis utvrđena u lisica $\mathrm{u}$ barem 24 europske zemlje (Oksanen i sur., 2016.). Važno je spomenuti kako u nekim od tih država novi slučajevi alveolarne ehinokokoze u ljudi bivaju prijavljeni svake godine pa je tako samo 2015. godine potvrđeno 135 slučajeva u šest zemalja, što je najveća ikad zabilježena brojka u Europskom sustavu za nadzor zaraznih bolesti (TESSy) (Anonymous, 2017.).

Uzimajući u obzir navedeno, te činjenicu da se ova parazitoza prema Direktivi 2003/99 o praćenju zoonoza i uzročnika zoonoza Europskog parlamenta i Vijeća smatra prioritetom prilikom nadzora, ne treba posebno naglašavati njezinu važnost s javnozdravstvenog stajališta. Svrha ovog rada je dati pregled najnovijih i najvažnijih spoznaja vezanih uz dijagnostiku i rasprostranjenost ove zoonoze $u$ Europi te ulogu divljih životinja u širenju alveolarne ehinokokoze.

\section{Morfologija i razvojni ciklus}

Odrasla trakavica E. multilocularis je hermafrodit, duljine tijela od 1,2 do 3,7 milimetara, koje se sastoji od skoleksa, tj. specijaliziranog organa za prihvaćanje sa siskama i dva reda kukica na rostelumu, vrata te strobile, koju čini četiri do šest članaka (proglotida), od kojih je samo zadnji gravidni (Roberts i Janovy, 2000.). Jajašca su ovalnog oblika (promjera 30$40 \mu \mathrm{m}$ ), obavijena debelom poprečno ispruganom ovojnicom i u njima se nalazi heksakantni embrio - onkosfera. Jajašca E. multilocularis, i drugih pripadnika roda Echinococcus, morfološki se ne mogu razlikovati od jajašaca ostalih pripadnika roda Taenia. Alveolarni ehinokok - larvalni stadij trakavice, sastoji se od mnoštva cista (vezikula) ispunjenih želatinoznim matriksom koje svojim oblikom podsjećaju na tumorozno tkivo. Karakteristična za E. multilocularis je germinativna membrana sa slabo razvijenom lamelarnom kutikulom što omogućava neprekidno bujanje cista i nastanak multivezikularne strukture u kojoj nespolnom diobom nastaju protoskoleksi, tj. invazijski stadiji za nositelja. Iako trakavica građom podsjeća na malu pasju trakavicu - E. granulosus, za razliku od nje, ima više kukica na rostelumu, vrećasti uterus s jajima koji se nalazi u zadnjem, tj. gravidnom članku, bez lateralnih ogranaka, a sam gravidni članak je kraći od pola duljine cijele trakavice. Diferencijalno dijagnostički važan je i položaj genitalnog otvora, koji se kod E. multilocularis nalazi kranijalnije u odnosu na sredinu gravidnog članka, dok ga u slučaju E. granulosus nalazimo kaudalnije (Roberts i Janovy, 2000.).

U Europi, u nositelje trakavice $E$. multilocularis ubrajamo: crvenu (Vulpes vulpes) i arktičku (Vulpes lagopus) lisicu, kunopsa (Nyctereutes procyonoides), vuka (Canis lupus) i čaglja (Canis aureus), a $\mathrm{u}$ posrednike ubrajamo glodavce: voluharice (Microtus arvalis), europskog smeđeg zeca (Lepus europaeus), bizamskog štakora (Ondatra zibethicus) i dabra (Castor fiber) (Oksanen i sur., 2016.). S obzirom na nositelja i morfologiju parazita, razvojni se ciklus može podijeliti na: strobilarni (prisutnost odraslih trakavica) i alveolarni stadij (prisutnost metacestoda). Glavni nositelji strobilarnog stadija su lisice koje se invadiraju hraneći se posrednicima, 
glodavcima u kojima se razvio fertilni ehinokok (alveolarni stadij), tj. ehinokok koji sadrži protoskolekse. Odrasla, spolno zrela trakavica parazitira $\mathrm{u}$ tankom crijevu lisice i ostalih divljih mesoždera te rjeđe u pasa i mačaka, dok larva (metacestoda) - alveolarni ehinokok, parazitira ponajprije u jetri posrednika glodavaca i ljudi. Posrednici se invadiraju konzumacijom hrane ili vode onečišćene jajašcima E. multilocularis. Probavni sokovi u želucu posrednika oslobađaju onkosferu iz ovojnice te ona dolaskom u tanko crijevo pomoću kukica buši njegovu stijenku. Dospijećem u limfu ili krv pasivno se prenosi u jetru, gdje se razvije u ehinokok. Za razliku od $E$. granulosus, kod kojega protoskoleksi invazijsku sposobnost postižu tek za šest mjeseci, ciste $\mathrm{s}$ protoskoleksima $E$. multilocularis postaju invazivne već za dva mjeseca (fertilni ehinokok). Kada invadiranog posrednika pojede prikladni nositelj, pod utjecajem pepsina oslobađaju se protoskoleksi koji se zatim u tankome crijevu nositelja razvijaju $u$ odrasle trakavice. Njihov broj može doseći i do nekoliko tisuća, a spolnu zrelost, kada se jajašca krenu izlučivati izmetom nositelja, dosežu nakon prepatentnog perioda od barem 28 dana. Peroralnim unošenjem jajašaca od strane posrednika taj se ciklus završava (Gottstein i sur., 2015.).

\section{Dijagnostika}

Dostupne su razne tehnike kako za post-mortem, tako i za in vivo detekciju trakavica E. multilocularis u mesoždera, na individualnoj razini ili na razini populacije. Post-mortem dijagnostika se bazira na pronalasku parazita tijekom razudbe i naknadnoj identifikaciji prema specifičnim morfološkim kriterijima kao i pomoću molekularnih metoda. Zlatnim standardom smatra se tehnika sedimentacije i brojenja (SCT - Sedimentation and Counting technique) (Eckert, 2003.), osmišljena na način da dopušta pregled kompletnog crijevnog sadržaja i detekciju vrlo malog broja parazita. Modificirane verzije tog postupka kao SVT (engl. shaking in a vessel technique) (Duscher i sur., 2005.) i SFCT (engl. scraping, filtration and counting technique) (Gesy i sur., 2013.) metode, pokazale su se još učinkovitijima u procesuiranju uzoraka te dijagnostičkoj osjetljivosti od SCT-a. Manje zahtjevna $\mathrm{u}$ smislu vremena i truda potrebnog za izvođenje je i IST (engl. intestinal scraping techniqe) metoda i njezine varijante, pogodne za epidemiološka istraživanja koja uključuju veliki broj uzoraka. Unatoč mnogim prednostima, za uspješnu post-mortalnu dijagnostiku potrebna je dobra očuvanost odraslog parazita, posebice $u$ područjima gdje se istodobno javljaju različiti pripadnici roda Echinococcus. Potrebno je poduzeti i specifične mjere opreza kako bi se spriječila mogućnost potencijalnog peroralnog unosa invazivnih jajašaca ehinokoka. Primjerice, crijeva moraju biti zamrznuta na $-80{ }^{\circ} \mathrm{C}$ najmanje dva dana prije daljnje manipulacije kako bi se osigurala inaktivaciju parazita (Carmena i Cardona, 2014.).

In vivo testovi, iako manje specifičnosti i osjetljivosti od post-mortalnih, sigurniji su za dijagnostičara i zahtijevaju manje vremena za provedbu. Pogodni su za obradu većeg broja uzoraka u jedinici vremena, što ih čini idealnima za epidemiološka istraživanja. Široku primjenu za otkrivanje antigena iz izmeta ima izravna ELISA koja je, prije svega, prikladna kod umjerenih do jakih parazitarnih invazija, dok kod nositelja invadiranih sa svega nekoliko parazita pokazuje slabije rezultate (Eckert, 2003., Carmena i sur., 2007.). Primjenjivost koprološke pretrage, s obzirom na nisku osjetljivost te nespecifičnost, odnosno nemogućnost razlikovanja jajašaca E. multilocularis od ostalih tenija je upitna. Ipak, kombinacijom ispiranja sadržaja crijeva preko sita i primjenom 
metode flotacije $\mathrm{s}$ otopinom cinkova klorida te naknadnom molekularnom identifikacijom pronađenih jajašaca, osjetljivost i specifičnost je moguće povisiti (Conraths i Deplazes, 2015.). Otkrivanje DNK ehinokoka $\mathrm{u}$ izmetu je metodologija visoke osjetljivosti i specifičnosti (Eckert, 2003., Dinkel i sur., 2004., Deplazes i sur., 2011.). Sukladno tome, dijagnostika koja se bazira na PCR-u prikladnija je i češće se koristi za potvrdu invazije u populacijama kad se sumnja na nisku prevalenciju parazita (Deplazes i sur., 2003.). Konačno, serološke metode za otkrivanje specifičnih protutijela nisu prikladne za potvrdu ehinokokoze u divljih mesoždera, osim kao eventualni potvrdni test $\mathrm{u}$ životinja $\mathrm{u}$ zatočeništvu, uz napomenu da je dokazana unakrižna reakcija sa srodnom malom pasjom trakavicom (Severin, 2012.).

\section{Rasprostranjenost i učestalost}

Smatra se da je povećanje populacije lisica u Europi u 90-tim godinama prošlog stoljeća, kao posljedica uspješnog provođenja oralnog cijepljenja protiv bjesnoće, dovelo do širenja ehinokokoze sjeverno i jugoistočno iz inače endemskih područja središnje Francuske, Švicarske, južne Njemačke i zapadne Austrije (Romig i sur., 2006., Vervaeke i sur, 2006., Davidson i sur., 2012.). Nejasno je ipak je li trenutna rasprostranjenost trakavice E. multilocularis rezultat toga što su ranije endemska područja prolazila nezamijećeno, zbog manjka nadzora ili neadekvatnih dijagnostičkih metoda, ili je uistinu u zadnjih 30-ak godina došlo do širenja te parazitarne invazije (Carmena i Cardona, 2015.).

$S$ porastom populacije lisica neizbježno dolazi i do njihovog pojavljivanja u urbanim sredinama, pa je tako prisutnost E. multilocularis zabilježena u lisica koje obitavaju u okolici Budimpešte (Casulli i sur., 2010.), Kopenhagena (Kapel i Saeed, 2000.), Ženeve (Fischer i sur., 2005., Repe- rant i sur., 2007.), Pariza (Combes i sur., 2012.), Praga (Martinek i sur., 2001.) i Züricha (Hofer i sur., 2000.). Ovakva situacija mogla bi omogućiti uspostavljanje sinantropskog ciklusa parazita održavanog između populacije glodavaca i domaćih životinja, ponajprije kućnih ljubimaca mesoždera koji se njima povremeno hrane (Reperant i sur., 2007.), povećavajući tako rizik prijenosa alveolarne ehinokokoze na ljude.

Osim porasta broja lisica i njihove urbanizacije, čimbenici poput sastava tla i njegova iskorištavanja, vegetacije, klimatskih promjena, prisutnosti prijemljivih posrednika navode se kao potencijalni okidači povećanja rizika od invazije s E. multilocularis u Europi (Oksanen i sur., 2016.).

Kako se ova trakavica smatra parazitom hladnijih klimatskih podneblja, a jajašca su joj veoma osjetljiva na isušivanje i visoke temperature, geološki i klimatski čimbenici imaju važnu ulogu u njezinu preživljavanju i širenju invazije (Veit i sur., 1995.). Primjerice, u Slovačkoj je najveća prevalencija E. multilocularis u lisica zabilježena na sjeveru zemlje, na pretežno brdovitim područjima u kojima prevladavaju šume četinjača, pašnjaci, niska prosječna godišnja temperatura $\left(4-8^{\circ} \mathrm{C}\right)$ i visok godišnji prosjek količine padalina (700-1300 mm) te pretežito ilovača koju karakterizira visoki postotak vlage (Miterpakova i sur., 2006.). Epidemiološke studije provedene na endemičnim područjima Francuske i Njemačke su pokazale slične rezultate (Raoul i sur., 2001., Tackmann i sur., 2001.).

Važno je naglasiti i potencijalnu ulogu ljudi u širenju te parazitoze manipulacijom životinjskim vrstama, kako uvođenjem divljih životinja na prostore gdje one ranije nisu obitavale, tako i premještanjem kućnih ljubimaca s nekontroliranim zdravstvenim statusom. Tako je primjerice prisutnost E. multilocularis $\mathrm{u}$ Śvedskoj i otkriće europskog genotipa parazita u Sjevernoj Americi rezultat pre- 
mještanja invadiranih pasa. Nadalje, unošenjem invadiranih dabrova iz Njemačke, parazit je unesen u Veliku Britaniju, a slični su slučajevi Japana i otočja Svalbard u Norveškoj, gdje su translociranjem invadiranih lisica paraziti uvezeni po prvi puta na te prostore (Casulli i sur., 2015.).

Zanimljivo je da je među različitim populacijama lisica u kojih je ustvrđena trakavica E. multilocularis, mali broj invadiranih životinja akumulirao najveću parazitarnu biomasu (Martinek i sur., 2001., Raoul i sur., 2001., Guislain i sur., 2008., Casulli i sur., 2010.). Novije studije su pokazale kako 21 - $25 \%$ invadiranih lisica nosi vrlo veliki broj odraslih parazita ( $>1000$ trakavica) s procijenjenih više od 30000 jajašaca otpuštenih u okoliš po životinji dnevno (Reiterová i sur., 2006., Hurníková i sur., 2009.). Ovi podatci naglašavaju epidemiološku važnost jako invadiranih životinja, tzv. „super širitelja“, koje pridonose većini kontaminacije okoliša parazitskim jajašcima. Ovo saznanje, u kombinaciji s ekološkim i biološkim faktorima, kao što su sastav tla i konfiguracija terena te dostupnost populacija prijemljivih posrednika, može uvelike utjecati na prijenos E. multilocularis na lokalnoj razini.

Najnovije dostupne informacije govore da je prisutnost E. multilocularis zabilježena u lisica i u ljudi u barem 24 europske zemlje, dok su slobodne od ehinokokoze Velika Britanija, Irska, Finska i Norveška (osim Svalbarda) (Oksanen i sur., 2016.). Prevalencija u lisica jako varira od zemlje do zemlje - najniže prevalencije zabilježene su u Danskoj (0,7 \%) (Enemark i sur., 2013.), Sloveniji i Švedskoj (ispod 1 \%), dok su prevalencije više od $10 \%$ zabilježene u Češkoj, Estoniji, Francuskoj, Njemačkoj, Latviji, Poljskoj, Slovačkoj i Svicarskoj (Oksanen i sur., 2016.). Prevalencija varira i od područja do područja unutar iste zemlje. Tako je u sjeveroistočnoj Francuskoj nizom istraživanja dokazana prevalencija između 17 i $63 \%$ (Raoul i sur., 2001., Guislain i sur., 2008., Robardet i sur., 2008., Umhang i sur., 2011., Combes i sur., 2012.), dok u Njemačkoj, ovisno o regiji stope invazije lisica i kunopasa variraju od $2 \%$ pa čak i do $80 \%$ (Tackmann i sur., 2001., Thiess i sur., 2001., König i sur., 2005., Berke i sur., 2008., Schwarz i sur., 2011., Denzin i sur., 2014.).

Iako se donedavno smatralo da jugoistočnu granicu rasprostranjenosti parazita u Europi čine Slovenija, Mađarska, Srbija i Rumunjska (Casulli i sur., 2010., Rataj i sur., 2010., Lalošević i sur., 2016., Siko i sur., 2011.), financiranjem programa nadziranja E. multilocularis od strane Ministarstva poljoprivrede, Uprave za veterinarstvo provedenog tijekom 2015. i 2016. godine, taj je parazit ustanovljen i u Hrvatskoj. Prema dostupnim saznanjima, lisice se u Hrvatskoj nikada ranije nisu sustavno pretraživale na E. multilocularis. U 238 uzoraka izmeta lisica odstrijeljenih tijekom 2015. i 2016. godine dokazom DNK parazita ustanovljena je prevalencija od $7,2 \%$. Većina invadiranih lisica uzorkovanih 2015. potjecala je iz zapadne i sjeverozapadne Hrvatske, što je ujedno i područje $s$ najvećom gustoćom zaraženih životinja. No, 2016. godine je vidljivo novo žarište invazije s pomakom prema istočnom i središnjem dijelu Hrvatske, odnosno granici s $\mathrm{BiH}$. Zanimljivo je da su tijekom obje godine pronađeni pozitivni uzorci na području Like na nadmorskim visinama višim od $400 \mathrm{~m}$, oko $18 \mathrm{~km}$ od obale Jadranskog mora (Beck i sur., 2018.). Nakon potvrde prisutnosti E. multilocularis u lisica, nametnulo se pitanje statusa čagljeva u Hrvatskoj. Prikupljeno je ukupno 29 lešina odraslih čagljeva čiji je crijevni sadržaj pregledan mikroskopski, pronađene trakavice analizirane su dodatno PCR-om te je potvrđena invazija jedne životinje s E. multilocularis 
(Sindičić i sur., 2018.) i to na području koje su Beck i sur. (2018.) definirali kao novo žarište. Također je vrijedno reći da je spomenuta lokacija oko 250 kilometara udaljena od Vojvodine $\mathrm{u}$ Srbiji, gdje su Lalošević i sur. (2016.), morfološkom identifikacijom parazita prikupljenih ispiranjem crijeva, ustanovili prevalenciju E. multilocularis od $14,3 \%$ u čagljeva. Posljednjih 15ak godina rasprostranjenost čagljeva u Hrvatskoj se povećala do te mjere da ih je moguće pronaći i u prigradskim područjima, zbog čega predstavljaju moguć izvor za uspostavljanje urbanog ciklusa. Važno je naglasiti i da je 2020. godine prvi puta dokazana prisutnost E. multilocularis u ljudi u Hrvatskoj te da je zbog nedostatka podataka o prisutnosti ovog parazita u Hrvatskoj bolest ispravno dijagnosticirana tek 2,5 godine nakon prve pojave simptoma $\mathrm{u}$ pacijenta (Dušek i sur., 2020.).

\section{Zaključak}

Iako su često prilično zanemarene $\mathrm{u}$ javnosti u odnosu na neke druge bolesti, parazitarne zoonoze su i u današnje vrijeme veliki problem koji predstavlja stalnu neposrednu ili potencijalnu opasnost za ljude, čak i one u najrazvijenijim zemljama. Alveolarna ehinokokoza, kao relativno rijetka, ali jedna od najopasnijih zoonoza u svijetu, svakako je tema koja zaslužuje pozornost veterinara, šumara, agronoma, lovaca i svih ostalih zvanja i zanimanja koja su zbog svoje profesije ili hobija jače izloženi potencijalnoj invaziji. Radi održavanja ove bolesti pod kontrolom, nužno je njezino stalno praćenje, obrada prikupljenih podataka s ciljem određivanja uspješnih mjera prevencije i suzbijanja širenja. Budući da su za održavanje ciklusa prijenosa alveolarne ehinokokoze primarno presudne lisice, čiji je broj u posljednjih nekoliko desetljeća u stalnom porastu, ne iznenađuje činjenica da se sve više pozornosti pridaje nadzoru kako te životinjske vrste, tako i drugih divljih životinja.

\section{Literatura}

1. Anon. (2017): Annual epidemiological report for 2015 - Echinococcosis. European Centre for Disease Prevention Control, Stockholm, Sweden.

2. BECK, R., Ž. MIHALJEVIĆ, R. BREZAK, S. BOSNIĆ, I. LOHMAN JANKOVIĆ and P. DEPLAZES (2018): First detection of Echinococcus multilocularis in Croatia. Par. Res. 117, 617-621.

3. BERKE, O., T. ROMIG and M. VON KEYSERLINGK (2008): Emergence of Echinococcus multilocularis among red foxes in northern Germany, 1991-2005. Vet. Parasitol. 155, 319-322.

4. CARMENA, D. and G. A. CARDONA (2014): Echinococcosis in wild carnivorous species: Epidemiology, genotypic diversity, and implications for veterinary public health. Vet. Parasitol. 202, 69-94.

5. CARMENA, D., A. BENITO and E. ERASO (2007): The immunodiagnosis of Echinococcus multilocularis infection. Clin. Microbiol. Infect. 13, 460-475.

6. CARMENA, D. and G. CASULLI, A. POSSENTI, G. and L. A. TORRE (2015): Echinococcus multilocularis infection in animals (GP/EFSA/AHAW/2012/01). EFSA supporting publication EN-882.

7. CASULLI, A., Z. SZELL, E. POZIO and T. SRETER (2010): Spatial distribution and genetic diversity of Echinococcus multilocularis in Hungary. Vet. Parasitol. 174, 241-246.

8. COMBES, B., S. COMTE, V. RATON, F. RAOUL, F. BOUÉ, G. UMHANG, S. FAVIER, C. DUNOYER, N. WORONOFF and P. GIRAUDOUX (2012): Westward spread of Echinococcus multilocularis in foxes, France, 2005-2010. Emerg. Infect. Dis. 18, 2059-2062.

9. CONRATHS, F. J. and P. DEPLAZES (2015): Echinococcus multilocularis: Epidemiology, surveillance and state-of-the-art diagnostics from a veterinary public health perspective. Vet. Parasitol. 213, 149-161.

10. DAVIDSON, R. K., T. ROMIG, E. JENKINS, M. TRYLAND and L. J. ROBERTSON (2012): The impact of globalisation on the distribution of Echinococcus multilocularis. Trends Parasitol. 28, 239-247.

11. DENZIN, N., A. SCHLIEPHAKE, A. FRÖHLICH, M. ZILLER and F. J. CONRATHS (2014): On the move? Echinococcus multilocularis in red foxes of Saxony-Anhalt (Germany). Transbound. Emerg. 61, 239-246. doi:10.1111/tbed.12026.

12. DEPLAZES, P., A. DINKEL and A. MATHIS (2003): Molecular tools for studies on the transmission biology of Echinococcus multilocularis. Parasitol. 127 (Suppl.) S53-S61.

13. DEPLAZES, P., F. VAN KNAPEN, A. SCHWEIGER and P. A. OVERGAAUW (2011): Role of pet dogs and cats in the transmission of helminthic zoonoses 
in Europe, with a focus on echinococcosis and toxocarosis. Vet. Parasitol. 182, 41-53.

14. DINKEL, A., E. M. NJOROGE, A. ZIMMERMANN, M. WÄLZ, E. ZEYHLE, I. E. ELMAHDI, U. MACKENSTEDT and T. ROMIG (2004): A PCR system for detection of species and genotypes of the Echinococcus granulosus-complex, with reference to the epidemiological situation in eastern Africa. Int. J. Parasitol. 34, 645-653.

15. DUSCHER, G., H. PROSL and A. JOACHIM (2005): Scraping or shaking - a comparison of methods for the quantitative determination of Echinococcus multilocularis in fox intestines. Parasitol. Res. 95, 40-42.

16. DUŠEK, D., A. VINCE, I. KURELAC, N. PAPIĆ, K. VIŠKOVIĆ, P. DEPLAZES and R. BECK (2020): Human Alveolar Echinococcosis, Croatia. Emerg. Infect. Dis. 26, 364-366.

17. ECKERT, J. (2003): Predictive values and quality control of techniques for the diagnosis of Echinococcus multilocularis in definitive hosts. Acta Trop. 85, 157-163.

18. ECKERT, J. and P. DEPLAZES (1999): Alveolar Echinococcosis in Humans: The Current Situation in Central Europe and the Need for Countermeasures. Parasitol. Tod. 15, 315-319.

19. ENEMARK, H., M. AL-SABI, J. KNAPP, M. STAAHL and M. CHRIEL (2013): Detection of a high-endemic focus of Echinococcus multilocularis in red foxes in southern Denmark. Euro Surveill. 18:20420.

20. FISCHER, C., L. A. REPERANT, J. M. WEBER, D. HEGGLIN and P. DEPLAZES (2005): Echinococcus multlocularis infections of rural, residential and urban foxes (Vulpes vulpes) in the canton of Geneva, Switzerland. Parasite 12, 339-346.

21. GESY, K., M. PAWLIK, L. KAPRONCZAI, B. WAGNER, B. ELKIN, H. SCHWANTJE and E. JENKINS (2013): An improved method for the extraction and quantification of adult Echinococcus from wildlife definitive hosts. Parasitol. Res. 112, 2075-2078.

22. GOTTSTEIN, B., M. STOJKOVIC, D. A. VUITTON, L. MILLON, A. MARCINKUTE and P. DEPLAZES (2015): Threat of alveolar echinococcosis to public health - a challenge for Europe. Tr. Parasitol. 31, 407-412.

23. GUISLAIN, M. H., F. RAOUL, P. GIRAUDOUX, M. E. TERRIER, G. FROMENT, H. FERTE and M. L. POULLE (2008): Ecological and biological factors involved in the transmission of Echinococcus multilocularis in the French Ardennes. J. Helminthol. 82, 143-151.

24. HOFER, S., S. GLOOR, U. MULLER, A. MATHIS, D. HEGGLIN and P. DEPLAZES (2000): High prevalence of Echinococcus multilocularis in urban red foxes (Vulpes vulpes) and voles (Arvicola terrestris) in the city of Zurich, Switzerland. Parasitol. 120, 135-142.

25. HURNÍKOVÁ, Z., M. MITERPÁKOVÁ and B. CHOVANCOVÁ (2009): The important zoonoses in the protected areas of the Tatra National Park (TANAP). Wiad Parazytol. 55, 395-398.

26. KAPEL, C. M. O. and I. SAEED (2000): Echinococcus multilocularis - en nyzoonotisk parasit I Denmark. Dan. Vet. 83, 14-16.

27. KÖNIG, A., T. ROMIG, D. THOMA and K. KELLERMANN (2005): Drastic increase in the prevalence of Echinococcus multilocularis in foxes (Vulpes vulpes) in southern Bavaria, Germany. Eur. J. Wildl. Res. 51, 277-282.

28. LALOŠEVIĆ, D., V. LALOŠEVIĆ, V. SIMIN, M. MILJEVIĆ, B. ČABRILO and O. BJELIĆ ČABRILO (2016): Spreading of multilocular echinococcosis in southern Europe: the first record in foxes and jackals in Serbia, Vojvodina Province. Eur. J. Wildl. Res. 62, 793-796.

29. MARTINEK, K., L. KOLAROVA and J. CERVENY (2001): Echinococcus multilocularis in carnivores from the Klatovy district of the Czech Republic. J. Helminthol. 75, 61-66.

30. MITERPAKOVA, M., P. DUBINSKY, K. REITEROVA and M. STANKO (2006): Climate and environmental factors influencing Echinococcus multilocularis occurrence in the Slovak Republic. Ann. Agric. Environ. Med. 13, 235-242.

31. OKSANEN A., M. SILES-LUCAS, J. KARAMON, A. POSSENTI, F. J. CONRATHS, T. ROMIG, P. WYSOCKI, A. MANNOCCI, D. MIPATRINI, G. LA TORRE, B. BOUFANA and A. CASULLI (2016): The geographical distribution and prevalence of Echinococcus multilocularis in animals in the European Union and adjacent countries: a systematic review and meta-analysis. Parasit. Vectors 9: 519.

32. RAOUL, F., P. DEPLAZES, N. NONAKA, R. PIARROUX, D. A. VUITTON and P. GIRAUDOUX (2001): Assessment of the epidemiological status of Echinococcus multilocularis in foxes in France using ELISA coprotests on fox faeces collected in the field. Int. J. Parasitol. 31, 1579-1588.

33. RATAJ, A. V., A. BIDOVEC, D. ZELE and G. VENGUST (2010): Echinococcus multilocularis in the red fox (Vulpes vulpes) in Slovenia. Eur. J. Wildl. Res. $56,819-822$

34. REITEROVÁ, K., E. DZIEMIAN, M. MITERPÁKOVÁ, D. ANTOLOVÁ, M. KOŁODZIEJ-SOBOCIŃSKA, B. MACHNICKA and P. DUBINSKÝ (2006): Occurrence of Echinococcus multilocularis in red foxes from the Carpathian regions of Slovakia and Poland. Acta Parasitol. 51, 107-110.

35. REPERANT, L. A., D. HEGGLIN, C. FISCHER, L. KOHLER, J. M. WEBER and P. DEPLAZES (2007): Influence of urbanization on the epidemiology of intestinal helminths of the red fox (Vulpes vulpes) in Geneva, Switzerland. Parasitol. Res. 101, 605-611.

36. ROBERTS, L. and J. JANOVY Jr. (2000): Foundatons of parasitology ( $6^{\text {th }}$ edition). New York: McGraw Hill.

37. ROBARDET, E., P. GIRAUDOUX, C. CAILLOT, F. BOUE, F. CLIQUET, D. AUGOT and J. BARRAT 
(2008): Infection of foxes by Echinococcocus multilocularis in urban and suburban areas of Nancy, France: influence of feeding habits and environment. Parasite 15, 77-85.

38. ROMIG, T., A. DINKEL and U. MACKENSTEDT (2006): The present situation of echinococcosis in Europe. Parasitol. Int. 55, (Suppl.) S187-S191.

39. SCHWARZ, S., A. SUTOR, C. STAUBACH, R. MATTIS, K. TACKMANN and F. J. CONRATHS (2011): Estimated prevalence of Echinococcus multilocularis in raccoon dogs Nyctereutes procyonoides in northern Brandenburg, Germany. Curr. Zool. 57, 655-661.

40. SEVERIN, K. (2012): Bolesti divljači. U: Veterinarski priručnik (Urednici: Herak-Perković, V., Ž. Grabarević, J. Kos) Medicinska naklada Zagreb. Str. 703-704.

41. SIKO, S. B., P. DEPLAZES, C. CEICA, C. S. TIVADAR, I. BOGOLIN, S. POPESCU and V. COZMA (2011): Echinococcus multilocularis in southeastern Europe (Romania). Parasitol. Res. 108, 10931097.

42. SINDIČIĆ, M., M. BUJANIĆ, I. ŠTIMAC, F. MARTINKOVIĆ, N. TUŠKAN, M. ŠPEHAR and D. KONJEVIĆ (2018): First identification of Echinococcus multilocularis in golden jackals in Croatia. Acta Parasitol. 63, 654-656.

43. TACKMANN, K., U. LOSCHNER, C. H. MIX, H. STAUBACH, H. THULKE, M. ZILLER and
F. J. CONRATHS (2001): A field study to control Echinococcus multilocularis-infections of the red fox (Vulpes vulpes) in an endemic focus. Epidemiol. Infect. 127, 577-587.

44. THIESS, A., R. SCHUSTER, K. NÖCKLER and H. MIX (2001): Helminth findings in indigenous raccoon dogs Nyctereutes procyonoides (Gray, 1843). Berl. Munch. Tierarztl. Wochenschr. 114, 273-276.

45. TORGERSON, P. R., K. KELLER, M. MAGNOTTA and N. RAGLAND (2010): The global burden of alveolar echinococcosis. PLoS Negl. Trop. Dis. 4, 722.

46. UMHANG, G., N. WORONOFF-RHEN, B. COMBES and F. BOUE (2011): Segmental sedimentation and counting technique (SSCT): an adaptable method for qualitative diagnosis of Echinococcus multilocularis in fox intestines. Exp. Parasitol. 128, 57-60.

47. VEIT, P., B. BILGER, V. SCHAD, J. SCHAFER, W. FRANK and R. LUCIOUS (1995): Influence of environmental factors on the infectivity of Echinococcus multilocularis eggs. Parasitology 110, 79-86.

48. VERVAEKE, M., J. VAN DER GIESSEN, B. BROCHIER, B. LOSSON, K. JORDAENS, R. VERHAGEN, C. DE LEZENNE COULANDER and P. TEUNIS (2006): Spatial spreading of Echinococcus multilocularis in red foxes (Vulpes vulpes) across nation borders in Western Europe. Prev. Vet. Med. 76, 137-150.

\section{Alveolar echinococcosis - spread of an invasion or zoonosis not previously diagnosed?}

Lana VUKRES-JAZIĆ, DVM, PhD, Magda SINDIČIĆ, DVM, Assistant Professor DVM, PhD, Miljenko BUJANIĆ, DVM, PhD, Franjo MARTINKOVIĆ, DVM, PhD, Assistant Professor, Tomislav GOMERČIĆ, DVM, PhD, Associate Professor, Dean KONJEVIĆ, DVM, PhD, Associate Professor, Faculty of Veterinary Medicine University of Zagreb, Croatia

Alveolar echinococcosis is a dangerous zoonosis caused by the larval stage of the tapeworm Echinococcus multilocularis. It is usually transmitted in a sylvatic cycle where red fox is the definite host and various rodents are intermediate hosts. Humans are an aberrant, dead-end host as they play no role in the life cycle of the parasite, though severe clinical symptoms of the disease may arise. Until the 1980s, only four countries were recognized as endemic areas for the disease (France, Germany, Switzerland and Austria). The latest research, however, suggests the presence of E. multilocularis in foxes in at least 24 European countries. Since alveolar echinococcosis is a deadly zoonosis if left undiagnosed and untreated, its spread is a matter of great public health concern. With the goal of keeping this disease under control, continuous epidemiological studies and monitoring of fox populations is required. Based on the data collected from numerous studies over the past two decades, this review article emphasizes the danger that alveolar echinococcosis poses as an emerging and reemerging disease in an increasing number of European countries, and the role of wild animals in its spread.

Key words: Echinococcus multilocularis; alveolar echinococcosis; wildlife; zoonosis 